\title{
Urgences
}

\section{Hôsha ou l'écran troué}

\section{Jean Forest}

Numéro 27, mars 1990

Images imaginaires

URI : https://id.erudit.org/iderudit/025572ar

DOI : https://doi.org/10.7202/025572ar

Aller au sommaire du numéro

Éditeur(s)

Urgences

ISSN

0226-9554 (imprimé)

1927-3924 (numérique)

Découvrir la revue

Citer ce document

Forest, J. (1990). Hôsha ou l'écran troué. Urgences, (27), 39-43.

https://doi.org/10.7202/025572ar d'utilisation que vous pouvez consulter en ligne.

https://apropos.erudit.org/fr/usagers/politique-dutilisation/ 


\title{
Hôsha ou l'écran troué
}

\author{
Jean Forest
}

pour MARYSE

ce Noël japonais

Je suis surpris par tous ces gens qui se contentent de si peu. Par le flux monotone de leur foule: où, semble-t-il, chacun aspire au bonheur du voisin. Qui donc s'inscrit en rupture de foule, seul, soucieux d'un bonheur taillé à sa mesure?

Évidemment, on pénètre fort peu dans les intérieurs, le cercle de nos voisinages est serré, lové autour de son axe. Les yeux, par contre, pour peu que vous aimiez la promenade dans les rues de la ville, accèdent aux intimités toutes les fois qu'on prend soin de n'en point tirer les rideaux. C'est la pléthore. Et c'est toujours pareil. La salon de l'un valant le salon de l'autre. De même le reste. La vie en fac-similé.

On aurait tort de croire qu'on y imite, latéralement, le voisin. On obéit, verticalement, à l'écran peint, celui dont Noël, par exemple, est l'écho fabuleux. On ne croit plus au petit Jésu s ni au Père Noël. Mais: "On se souvient." Comment c'était, déjà ?... Ah! oui, oui, attendez que je me souvienne... Ça y est! Nous y sommes... Croit-on!

Et s'évoque alors un décor parlant, où seuls les yeux, et les oreilles, se trouvent apostrophés. Une scène, des personnages, un sketch comme frappé de paralysie, un tableau vivant. Et logiquement, de ces corps fossilisés, émane une parole comprimée. Comme dans un étau. On tend l'oreille, forcément. C'est la Scène.

La saison est riche de ce dont je vous parle. Songez, par exemple, à la crèche. Le bœuf et l'âne. Sous l'arbre de Noël. Et justement, voici une contraction de parole: NOËL n'est-il pas ce qui nous reste, énigmatique, du compréhensible NATALIS DIES? Le «jour de naissance». La naissance de qui ? Je vous le donne en mille.

Et puis la dinde, énorme toujours, gonflée de sève, la peau craquante, arrosée, fumante. Au père d'officier, quand la mère a déposé le volatile devant lui. Autour de la table, les 
enfants, d'une famille toujours nombreuse. C'est la Scène des noces de Cana.

À son heure, le temps passe si vite, entre Noël et Pâques (Pâques, c'est le "passage "), changement de décor. Intervient la Dernière Scène. La scène des Adieux. Jésus, Judas, Jean, les autres: le festin, là-bas. Le pain, le jus, la sauce grasse, on mange avec les doigts. Judas, va, fais ce que dois, laisse braire... Les peintres ont mille fois croqué cet instant comprimé de la Scène, où l'on parle si peu de cette mort qui rôde. Sur l'écran de la peinture occidentale.

Vous connaissez la suite: la croix, le vinaigre, le sang changé en eau, la mère. Nous regardons, intensément, l'homme qui meurt, accueillons ses dernières paroles à la mère qui pleure son beau doux fils. Tableau vivant de la douleur, sur l'écran. Par centaines de millions, les Hommes ont vu Jésus, en eux, naître, se battre et mourir. Et à ses pieds leur mère, sur la toile des douleurs.

Toutes scènes vécues dans la petite enfance, si l'on sait bien y regarder. Toutes, avant que ne naisse l'adulte. Toutes, trop humaines: où rien ne figure la Nature, le Reste, tout ce qui n'est pas le reflet de notre nombril. Scènes fascinantes, autant que mortelles. Les Hommes s'en ennuient, en meurent, bien que leur âge ne soit pas échu.

Et par milliards, aujourd'hui, dans un empire sur lequel jamais le soleil ne se couche, ils allument les télés, pour que rayonnent les petits écrans. Déçus, nous regardons se dérouler la petite monnaie des scènes primitives. Dynastie, Dallas, Dodo. Si peu de chose. Pour un si peu de sens.

Paralysés, les hommes ne vivent plus que par leurs yeux, fixes; que par leurs oreilles, bourdonnantes. L'écran n'a pas d'odeur. Non plus que de chaleur. Insipides, les festins qu'on y dévoile, radicalement, n'ont aucun goût.

Le sang n'a plus le goût du sel. La chair n'y fume pas. Le cœur de l'homme, contre la femme, n'y bat point. Des ombres coloriées, un espace restreint: celui d'une toile, un tableau vivant, où s'échangent les plus comprimées des répliques. Le tout pourrait tenir sur la pointe d'une aiguille et n'occuper qu'une seconde.

L'Homme, nostalgique des Noëls aspirant à ses Pâques, sentant le bagne où il végète, $y$ rompt avec sa vie, rue dans 
les brancards, crie, pleure, se bronze l'épiderme, mange, mange, mange, se défonce en se piquant, se tue, tue: décharge, parfois, son arme. Son désir, au point mort, fait hurler le moteur, emballé, de son immobile existence. Sa vie, alors, tout comme à la télé. Où l'homme, ivre de son miroir, meurt du désir qu'il a de retourner dans le ventre de sa mère, où conjuguer Noël à Pâques. Certes, il ignore qu'il se verrouille ainsi, dans la prison des Écrans peints, issus de son enfance.

\section{$* * *$}

Au monastère, à Kyoto, l'encens brûle, discret. Pour peu que le vent soit debout, oscillent les coniferes: leur bruissement chavire les tympans, l'encens suit. Chaque heure modifie le chatoiement séculaire des vernis, et craquent les bois anciens. Au dojo, quand fléchissent les jambes et que tombent les postérieurs, s'enfoncent, s'enfoncent les coussins de la méditation, comme autant de petits poufs, dans le chahut des robes, la castagnette des os et des bois. À peine un lumignon: et les surfaces réfléchissent une Scène de kaléidoscope. Plus tard, le bain chaud, l'eau, entre les lattes, le clapotis des corps; le thé, les pruneaux, le riz discret, la séduction des pâtes, comme une chair huilée. Le chien aboie, le jardinier converse avec la poussée germinante; les carpes dans l'étang, le gong, la louche, bruyamment, les lèvres s'y désaltérant.

Le feu, comme enfoui dans le sol, craquette. Pas d'arme à feu. Le passage des secondes, dans les oreilles vives, les yeux caressés de soleil et de lune, la chaleur et le froid des saisons sur la peau exposée, la parole, le refus de discourir, le non définitif au placotage. Le trou, dans l'Écran. Le regard porte, enfin, si loin, au-delà du Golgotha.

$$
\text { *** * }
$$

Quatre ans durant, à la suite de sa conversion, Hôsha avait appris à désapprendre et nourri son refus du trou dans l'écran peint.

Vingt ans durant, pourtant, ses yeux, exorbités, ses oreilles, enflammées, jamais ne l'avaient pu repérer. Peutêtre n'y était-il qu'en germe? Vingt ans durant, ou trente, ou même un millénaire, oui, sans doute, Hôsha n'avait vu, 
n'avait lu, dans les signes, que la douleur des siens. Toutes portes fermées, toutes fenêtres closes. Et chaque jour, l'écran maternel, où rejouer la Nostalgie. Un rôle lui était, dans cette Scène, éternellement dévolu. De sa peau tendre, on l'avait privé: et son corps ne sentait plus rien. De son nez, il n'arrivait plus à se guider que vers le soufre. De sa langue, dure, sèche, écaillée, ne sortaient que de rares onomatopées, grinçantes, faute d'huile sainte. Ses yeux, paupières retranchées, ses oreilles, offertes dans leur impuissance même à se refermer, avaient dévécu, captifs, captives de l'Écran. Son roman familial. Ô certes, ni Noël ni Pâques !

Tous ceux-là, tout autour, sans fin, sur l'écran de sa tribu, soucieux mortellement de plaire, au regard aveugle posé sur eux: et un jour il eut peur. Tous ces objets, à étaler, sous le regard de ceux qui, en retour, afficheraient les mêmes: leur regard frelaté. Tablettes mentales surchargées, d'épaves et de bruits, sans faim, pour un festin dépourvu d'appétit. Il cria. Sa langue, croustillante, émit le cri du bois malmené par l'orage. Il fuit. Au bout de longues heures, ses jambes de bois le déposèrent, meurtri, sur le pas de sa porte. À force de poignets, il se toua, là, dans la rue.

Le froid creva sa peau: de son sang, il traça sur le pavé d'inouïs idéogrammes: sa langue y reconnut le goût du sel, il traîna, de son nez, dans les bavures d'immondices, vomit, reconnut la chaleur, s'enduisit de ses déjections: il reprenait ses sens. Les gens, peu avertis, il va sans dire, ne firent pas attention aux sillons qu'il placardait dans les rues de sa ville. Lui, rampa.

La rage. Il connaissait enfin la rage. Son cœur se fit entendre, à ses oreilles et à sa peau. Son nez fleurit, ses oreilles explosèrent, de sa langue il s'entraîna à s'adonner aux cris. Il heurta deux sandales, de front, décidées à ne pas lui céder le passage. De sa sueur, tant l'effort pour regarder là-haut fut grand, il créa sous ses joues un étang.

Là-haut, au sommet d'une robe taillée comme dans la terre, un homme le regardait, d'un regard apaisé: aucun son ne sortit de sa gorge. Hôsha hurla. De ses dents, il essaya de mordre les pieds de cet homme, mais ne put, sa nuque étant si raide. Il hurla. Ses vociférations pénétrèrent, toutes, sans exception, dans les trous de cet homme, qu'il avait aux oreilles. 
Il fallut quelques années pour apaiser ses hurlements. Les arroseuses balayèrent son sang et ses sillons. Lui articula quelques fracas de voix les uns aux autres. Jamais l'autre ne souffla mot. Hôsha s'agrippa aux oreilles, aux gigantesques pavillons tournés vers lui, exclusivement.

Il fallut d'autres années, quand il eut découvert à quoi pouvaient servir les bruits de sa gorge, articulés les uns aux autres, pour dépeindre l'Écran de sa maison natale. Un jour, son cri fut si furieux que la toile du temple s'en trouva déchirée. Il aperçut alors les arbres qu'elle lui avait cachés: dès lors, ses jambes le portèrent. Il entendit le murmure du ruisseau, sa salive lui revint. Il s'y laissa tomber, ses plaies se refermèrent. Au soleil, à la lune, il offrit les pores de sa peau: leur parfum lui fut rendu.

À une moniale qui passait, le dernier jour, il demanda la charité. Elle, saisie de compassion, sous le regard éteint de l'homme à la couleur de terre, le dévêtit, ouvrit ses jambes, introduisit son sexe dans la porte qui s'ouvrait en elle. Hôsha s'y engagea. Ayant franchi son seuil, sitôt il déboucha dans l'ombre d'un figuier, à l'orée du monastère, dont, humblement, tout vibrant de ses sens enfin reconquis, il ouvrit le portail avant de bénir, de son sperme, la Terre sa vraie mère, enfin découverte.

Hôsha venait de naître. 